\title{
Peculiarities of Printing on Paper with Addition of Licorice Cellulose
}

\author{
HALIMA BABAHANOVA* \\ RECEIVED ON 30.07.2015 ACCEPTED ON 14.12.2015
}

ABSTRACT

This study examines the possibility of using paper based on lint cellulose with addition of licorice cellulose for printing. The physical, mechanical and printing characteristics of paper, were studied towards this end. The addition of licorice cellulose components into the lint cellulose composition changed the surface nature and paper structure, which are defining phenomena of humidification, adsorption, adhesion, ink penetration and swelling. A reduction of paper sponginess by $15 \%$ increases the resolution capability - smoothness. This stimulates the provision of image high legibility. According to the research of the results of paper whiteness and opacity which define paper printing properties, it is possible to conclude that the research paper is fit for printing of single-color outputs. The use of licorice cellulose in cellulose-paper industry will solve the problem concerning not only raw materials but the ecology at the same time due to utilization of licorice root waste and use of hydrogen peroxide instead of carcinogenic sodium hypochlorite.

Key Words: Quality of Printing, Paper, Cellulose, Optical Density, Ink Trapping.

\section{INTRODUCTION}

$\mathrm{P}$ aper printability, is determined by printing properties, which are characterized by optical characteristics of a printed copy National Standard [NSt 13-299-87]. The change of ink transfer quantity from plate to paper has an influence on optical density of printed copy and printing quality. They are due to nun-uniformity of the paper. The structure of the print paper's surface is one of the most important properties as a bearer of printed image. First of all this determines the settling ability of surface, that is, the possibility to reproduce separately, with quite high degree of exactness and legibility, the printing elements of definite size [2-5]. The addition of other fiber semiprocessed materials into paper composition are essential factors, changing paper surface structure and improving its quality. The problem of studying the degree of influence on printing characteristics of used paper raw materials and process parameters of its production are examined in the system «Paper machine - Paper - InkPrinting machine - Printed copy» (Fig. 1.). In the given system for research the output, resulting parameters are quality indices of printed copies, and the input (factor) initial raw materials for paper production. It is known, that all fiber materials of different origin may be used for paper production. The primary task is not in choosing the material but in using material, which must be enough for converting and it is possible to produce printing paper. Uzbekistan is a cotton country where there are two manufactures of lint cellulose - Ferganagh ñhemical plant of furan compounds and Iangiulskay cellulose-paper factory.

The molecular structure of lint cellulose (linearity and maintenance of large number of hydroxyl groups) provide

\footnotetext{
* Department of Computer Science, Tashkent Institute of Textile \& Light Industry, University of Benin, Benin City, Nigeria.
} 
fibers with flexibility, network in sheet, capability to fibrillation and establishment of hydrogen bonds. Density $1.52-1.54 \mathrm{~g} / \mathrm{nm}^{3}$ degree of polymerization $n-12000$. Fibers of cotton bear breaking strain up to $412 \mathrm{mPa}$.

The use of lint cellulose in cellulose-paper industry of Uzbekistan Republic, the country of limited timber resources, provides the possibility of producing different paper types with high saturating capacity and chemical uniformity. They are successfully being used for production of lasting valuable types of paper. Nowadays non-wood types of raw materials, can be used for production of cellulose and chemical thermo-mechanical grammage, but they are not used. The resources are immense due to yearly replenishment. For many decades Tashkent institute of textile and light industry has been carrying out research on the use of non-wood raw materials for production of different cellulose-paper products. Considerable practical experience was accumulated on their processing.

A study has been made of the specific peculiarities of morphological build-up, chemical composition and use of fiber semi-processed materials from waste products. Waste products were taken from textile industry: spoils of real silk [6-8]; from agricultural industry [9-11]; from chemical fibers [12-13]. The results of this research showed workability and practical possibility of the use stems and waste converting in production of fiber semi-processed materials for paper manufacture. Their printing properties were examined too [14-15]. One of the licorice types common licorice grows in the river basin of Amu Darya. It is spread in eastern and southern regions of Kazakhstan,
Kyrghyzstan, and also in southern steppe regions of Western and Eastern Siberia. Licorice is perennial plant, the root mass of which incomparably exceeds the footstalk weight. As the years go by, the licorice root system occupies large areas: its quickly growing shoots can extend for up to dozens of meters throwing out footstalks from the buds on the ground surface. The licorice root is one of the oldest pharmaceuticals. Even though, one would think, extensive application of licorice in medicine and in other branches, research is being carried out concerning the use of waste licorice root in the ñållulose-paper industry [16-17]. As initial raw material, the cotton cellulose was used for paper production with given printing characteristics. It is produced from cotton lint (Uzbekistan) with cellulose addition of waste licorice root, which is unfit for use on direct application. However, after appropriate treatment, they can be used as raw materials for paper production in accordance with the developed technology. In the work, the study has been made of influence regularities with licorice cellulose addition on printed copy optical density, printing quality.

\section{METHODS}

For sheet formation it has been received a cellulose from licorice root waste according to the developed method under different conditions [17]. To calculate paper density, we used the mass values of square meter and paper thickness and defined it according to NSt 13199-67. The paper ash content was determined in accordance with NSt 7629-77. Paper sponginess, medium size of voids, degree of sizing, smoothness on the Bekka gauge have been determined according to description shown in [18].

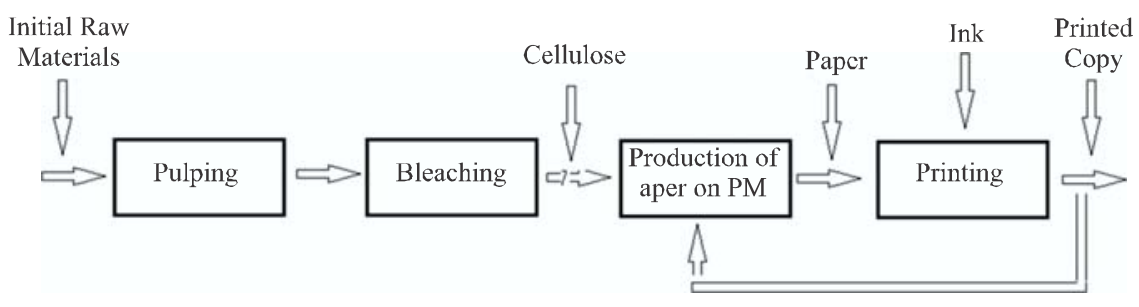

FIG. 1. SYSTEM APPROACH TO CONTROL PAPER-PRINTING CHARACTERISTICS

Mehran University Research Journal of Engineering \& Technology, Volume 36, No. 1, January, 2017 [p-ISSN: 0254-7821, e-ISSN: 2413-7219] 
The fastness has been determined according to NSt 13199-67. The paper printing characteristics with addition of licorice cellulose ink acceptance and printing through, bonding paper strength and ink trapping have been determined according to methods [19].

\section{RESULTS AND DISCUSSION}

In different kinds of raw material the content of cellulose is within $40-60 \%$, in straw footstalks $30-35 \%$, cotton fibers contain $90-95 \%$ of cellulose. According to indices of cellulose from licorice root waste (Table 1) it is shown that licorice contains $85 \%$ of cellulose, i.e. it is quite suitable for paper production.

The use of licorice cellulose in cellulose-paper industry will solve the problem concerning not only raw materials but the ecology at the same time due to utilization of licorice root waste and use of hydrogen peroxide.

The optimum amount of water (from 4.4-6\%) in the paper will provide printing process without complications. Short weight of cellulose licorice filled mesh cell of the long fibers, which is confirmed by the values of sponginess. By medium size of voids of the paper have a microstructure (0.01-0.05 microns). Research roughness showed that matte paper.

It is known that the physical tincture increment takes place because of coloring creeping, paper sponginess

TABLE 1. CHARACTERISTIC OF USED CELLULOSE SAMPLES

\begin{tabular}{|c|c|c|c|}
\hline No. & Indices of Cellulose & $\begin{array}{c}\text { Cotton } \\
\text { Cellulose }\end{array}$ & $\begin{array}{c}\text { Licorice } \\
\text { Cellulose }\end{array}$ \\
\hline 1. & Weight percentage of $\alpha$-cellulose & 99.2 & 85.0 \\
\hline 2. & Degree of whiteness (\%) & 90.0 & 87.5 \\
\hline 3. & Viscosity (cP) & 650 & 250 \\
\hline 4. & Weight percentage of trash (\%) & 0.03 & 0.02 \\
\hline 5. & Humidity (\%) & 8.0 & 8.0 \\
\hline
\end{tabular}

and other reasons. As for optical increment - it happens due to absorption by printed elements margins of a scatter light in paper thickness, which penetrates in it through voids. The analysis of paper properties (Table 2) containing licorice and cotton cellulose reaffirms the possibility of using cellulose as additive into paper composition. This improves its printing properties and decreases paper sponginess that is so necessary for providing image high legibility. In order for the printing inks penetrating into paper did not decrease the optical effectiveness of the given ink quantity, at the same time decreasing the color gamut, it is necessary that the paper opacity was more than $80 \%$.

According to the research of the results of paper whiteness and opacity (Fig. 2) which define paper printing properties, it is possible to conclude that the research paper is fit for printing of single-color outputs.

The evaluation of the diagram influence on adding licorice cellulose with different percentage ratio on paper properties revealed optimal composition on ratio of cotton and licorice cellulose of paper No. 3 10:2 and paper No. 4 10:3 (Fig. 3). To conclude, the addition of licorice cellulose into paper composition results in increase of smoothness, mechanical strength by $15 \%$, decrease of sponginess by $8,5 \%$. The paper under investigation has medium size void structure.

According to optical density of printed copies $\mathrm{D}_{\mathrm{pc}}$ and ink quantity, which passed on paper, we characterized ink acceptance and its capability to oppose «printing through», which were defined during printing with fixed ink thickness on a plate.

Fig. 4 shows the increase of licorice cellulose quantity leads to the increase of printed copy optical density. 
Microstructure of this paper provided ink uniform distribution on the surface of image elements. The structure of licorice cellulose provides high resolution capability, i.e. the possibility of scanning of small image details. This improves paper printing properties, its capability to ink acceptance, which defines the printed copy quality.
Ink trapping shows (Fig. 5) that for all samples more than $50 \%$ of ink passes from a plate. The ink transference from a plate onto a paper is increased with increasing of licorice cellulose content in it.

Thus, the research showed that addition of licorice cellulose into paper mass from cotton cellulose produces positive influence on paper printing properties.

TABLE 2. PAPER CHARACTERISTIC BASED ON COTTON AND LICORICE CELLULOSE

\begin{tabular}{|c|c|c|c|c|c|c|}
\hline \multirow{2}{*}{ Name of Indices } & \multicolumn{5}{|c|}{ Paper by Ratio of Cotton Cellulose : Licorice Cellulose } \\
\cline { 2 - 7 } & $10: 0$ & $10: 1$ & $10: 2$ & $10: 3$ & $10: 4$ & 10.5 \\
\cline { 2 - 7 } & No. 1 & No. 2 & No. 3 & No. 4 & No. 5 & No. 6 \\
\hline Weight of one square meter (g) & 81.0 & 85.0 & 84.0 & 85.0 & 82.0 & 84.0 \\
\hline Thickness (mm) & 0.099 & 0.100 & 0.095 & 0.080 & 0.101 & 0.096 \\
\hline Humidity (\%) & 4.40 & 6.00 & 4.50 & 4.41 & 4.62 & 4.50 \\
\hline Sponginess (\%) & 45.9 & 42.7 & 42.9 & 40.5 & 46.3 & 42.1 \\
\hline Sizing (mm) & 0.25 & 0.25 & 0.25 & 0.25 & 0.25 & 0.25 \\
\hline Medium size of voids ( $)$ & 0.044 & 0.024 & 0.031 & 0.030 & 0.041 & 0.033 \\
\hline Density (g/sm) & 0.82 & 0.86 & 0.88 & 0.89 & 0.84 & 0.87 \\
\hline Bulkiness (sm 3 g) & 1.21 & 1.16 & 1.14 & 1.12 & 1.19 & 1.15 \\
\hline Roughness (mL/min) Felt Side & 362 & 350 & 340 & 340 & 330 & 315 \\
\hline Roughness (mL/min) Wire Side & 631 & 618 & 600 & 594 & 581 & 580 \\
\hline Tearing strength (mN) & 400 & 412 & 438 & 457 & 472 & 486 \\
\hline Breakdown force (N/15 mm) & 85 & 80 & 76 & 72 & 65 & 59 \\
\hline Stretch at breaking point (\%) & 2.8 & 2.6 & 2.5 & 2.4 & 2.1 & 2.1 \\
\hline
\end{tabular}

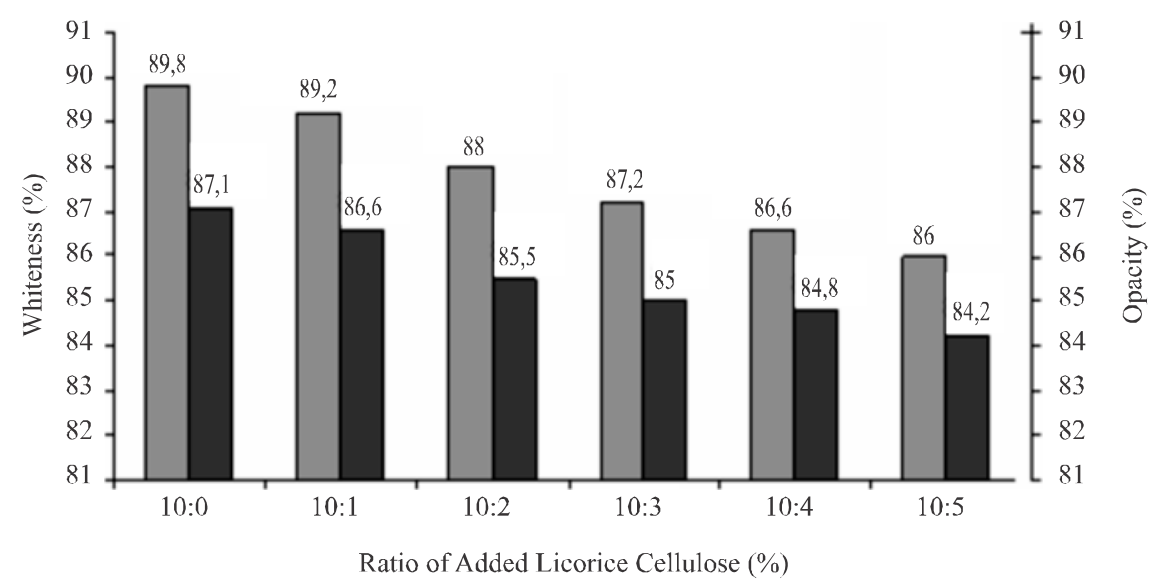

FIG. 2. DIAGRAM OF CHANGING WHITENESS AND OPACITY FROM PERCENTAGE RATIO OF ADDEDLICORICE CELLULOSE 


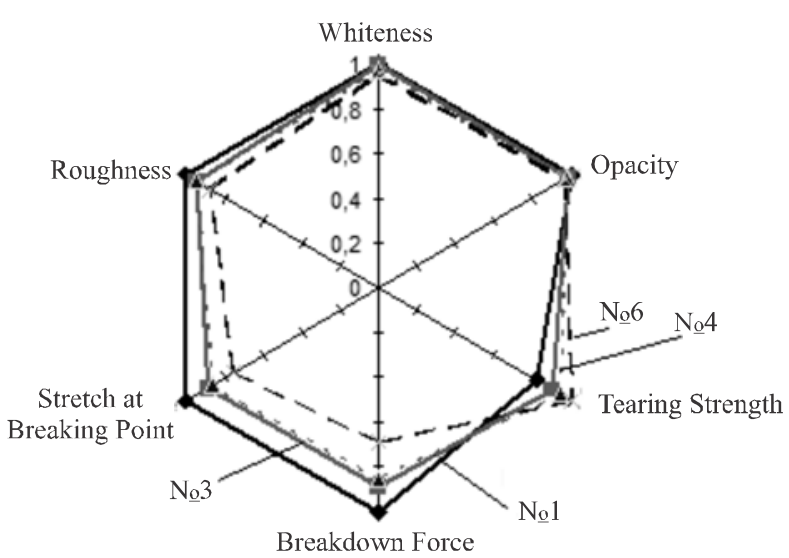

FIG. 3. DIAGRAM OF CELLULOSE RAW INFLUENCE ON PAPER PROPERTIES: NO. 1 - PAPER BASED ON COTTON CELLULOSE, NO. 3-PAPER BASED ON COTTON AND LICORICE CELLULOSE UNDER PROPORTION OF 10:2, NO. 4-UNDERPROPORTION OF 10:3, NO. 6-UNDER PROPORTION OF 10:4

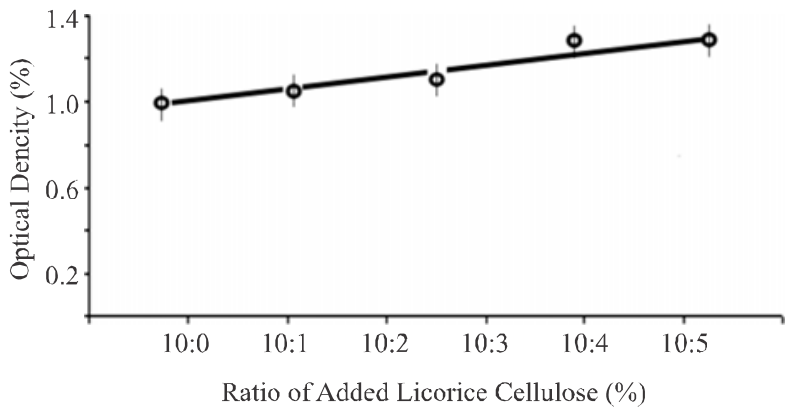

FIG. 4. DEPENDENCE OF PRINTED COPY OPTICAL DENSITY FROM PERCENTAGE RATIO OF ADDED LICORICE CELLULOSE

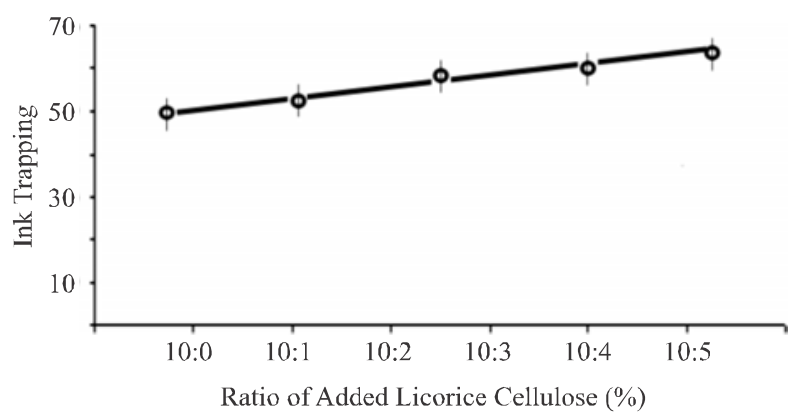

FIG. 5. DEPENDENCE CURVE OF INK TRAPPING FROM RATIO OF ADDED LICORICE CELLULOSE

\section{CONCLUSION}

The experimental results proved that paper based on cotton cellulose with addition of licorice cellulose can be used for printing of single-color outputs.
By studying physical, mechanical and printing paper properties it has been established that a reduction of paper sponginess by $15 \%$ increases the resolution capability smoothness and provides high legibility of image.

\section{ACKNOWLEDGEMENT}

This work is financially supported by State Program of Scientific and Technical Projects under Grant No.3-08, Uzbekistan.

\section{REFERENCES}

[1] National Standard Paper, "Gap Heterogeneity", Indices Nomenclature, NSt 13-299, 1987.

[2] Kozarovitsky, D.A., "Paper and Ink in Printing Process", Book, 1965.

[3] Kipphan, H., "Quality and Productivity Enhancement in Modern Offset Printing, Polygraph International, Special Print”, pp. 3-93, Germany, 2003

[4] Smirh, M.K., "Formation Potential of West Coast Kraft Pulps", Pulp and Paper, Volume 87, No. 10, pp. 387-394, Canada, 2007.

[5] Buczynski, L., and Klicinski, E., "Analize of Image Quality Parameters on Thermal NIP 20: Paper as Proposal to Extension Standard ISO/IES 13660/IS\&Ts", International Conference on Digital Printing Technologies, pp. 997-1000, 2004.

[6] Alimova, H.A., "Wasteless technology of silk treatment”, Science, Tashkent, 1994.

[7] Guliamov, A.E., "Working out of Technology on Preparation Silk Wastes for Paper Production”, Dissertation for Candidate of Technical Science, pp. 134, Tashkent, 1997.

[8] Babahanova, H.A., "Influence of Printing Methods on Paper Charecteristics from Wastes of Textile Industry", Textile, No. 4, pp. 59-63, Tashkent, 2010.

[9] Mirzaeva, M.B., and Babahanova, H.A., "Characteristics of Paper on the Basis Cotton and Cellulose from Annual Plants", Bulletin of Young Scientists, SPSUTD Part-1, Natural and Technical Sciences, pp. 98-101, Sankt-Peterburg, 2012. 
[10] Mirzaeva, M.B., and Babahanova, H.A., "Factors Influencing on Paper Specific Characteristics of Concrete Designation", News of Higher Educational Establishments, Problems of Graphic Arts and Publishing, Volume 2, pp. 13-17, Moscow, 2013.

[11] Kuzmich, V.V., "Influence of Various Raw Material and Technological Regimes of its Recycling on Qualitative Indices of Semi-Finished Product used for Package Printing”, Science \& Technique, Volume 4, 2014.

[12] Kamalova, C.P., Eshbaeva, Y.G., and Kamilova, C.D., "Working out of Optimal Preparation Conditions of Cocoon Reeling Manufacture Wastes for Paper Production", Textile Problems, Volume 3, pp. 66-68, Tashkent, 2012.

[13] Ềmalova, N.D., and Eshbaeva, Y.G., "Paper Production from Fiber Wastes of Acetyl Cellulose", Textile Problems, Volume 1, pp. 49-52, Tashkent, 2010.
[14] Babahanova, H.A., "Paper Printing Characteristics with Components of Silk Fibers and Kenaph", Ph.D. Thesis, pp. 132, Tashkent, 2000.

[15] Babahanova, H.A., and Nabiev, D.C., "Modelling of Quality Evaluation of Research Paper Properties", Materials of IX International Scientific - Practical Conference on Achievement of High School, pp. 37-43, Bulgaria, 17-25 November, 2013.

[16] Nabiev, D.N., Nabiev, I.A., Babahanova, H.A., and Shahidova, F.H., "Method of Cellulose Production", Patent IAP 04879, Uzbekistan, 2014.

[17] Shahidova, F.I., and Babahanova, H.A., "Paper Based Cotton and Licorice Cellulose", Graphic Art, Volume 2, pp. 58-59, Moskow, 2011.

[18] Shahkelidian, B.N., and Klimova, E.D., "Graphic Art Materials", Paper and Binding Materials, Part-1, Moskow, 1992.

[19] NSt 24356-80, Paper, "Method of Printing Characteristics Determination". 